\title{
Formulation and In vitro Evaluation of Oral Floating Tablets of Salbutamol Sulphate: Comparison with Effervescent Tablets
}

\author{
Md. Haider Ali ${ }^{1}$, Mohiuddin Ahmed Bhuiyan ${ }^{2}$, Md. Selim Reza ${ }^{3}$ and \\ Samira Karim ${ }^{1}$ \\ ${ }^{1}$ Department of Pharmacy, World University of Bangladesh, 151/8, Green Road, Dhaka-1205, Bangladesh \\ ${ }^{2}$ Department of Pharmacy, University of Asia Pacific, 74/A Green Road, Dhaka-1215, Bangladesh \\ ${ }^{3}$ Department of Pharmaceutical Technology, University of Dhaka, Bangladesh
}

(Received: August 02, 2016; Accepted: November 11, 2016; Published (web): December 27, 2016)

\begin{abstract}
The aim of this research was to develop and evaluate gastric floating tablets of salbutamol sulphate. The oral delivery of anti-asthmatic salbutamol sulphate tablets were facilitated by preparing floating dosage form which could increase its absorption in the stomach by increasing the gastric residence time of the drug. Floating tablets were formulated by using different polymers like carbopol, xanthan gum, HPMC-K4 MCR and HPMC- K100 MCR with different proportions. A comparative study of normal effervescent tablets of salbutamol sulphate had also been done. The prepared tablets were evaluated for all their physicochemical properties and in vitro buoyancy study. In vitro dissolution studies of the formulations were done in $\mathrm{pH} 6.8$ phosphate buffer using USP apparatus 2 (paddle method) at $50 \mathrm{rpm}$. Percent drug release of the formulations (F-1 to F-11) was from 87.34\%- 99.12\% after 12 hours. From the results, F-11 was selected as an optimized formulation based on $12 \mathrm{~h}$ drug release which showed minimal floating lag time and maximum floating time. On the other hand, 100\% drug was released within 2 hours from the F-12 of effervescent salbutamol sulphate tablets in which polymer was absent while gas generating sodium bicarbonate and citric acid were present. The results of the study were consistent and may encourage formulating similar dosage form with other drugs.
\end{abstract}

Key words: Salbutamol sulphate, floating tablets, in vitro buoyancy lag time, in vitro dissolution.

\section{INTRODUCTION}

Gastric emptying of pharmaceutical dosage form is an extremely variable process and ability to prolong and control the emptying time is a valuable asset for dosage forms, which reside in the stomach for a longer period of time than conventional dosage forms. Several difficulties are faced in designing controlled release systems for better absorption and enhanced bioavailability. ${ }^{1}$ The floating drug delivery systems can retain drugs in the stomach for prolonged time to improve the oral bioavailability of the drugs that have site-specific absorption from the stomach or upper part of the small intestine. These systems help in continuously releasing the drug in the

Correspondence to: Samira Karim

Phone: +88-01670802337

E-mail: k.samira37@yahoo.com

Dhaka Univ. J. Pharm. Sci. 15(2): 203-208, 2016 (December) stomach, thus ensuring optimal bioavailability. ${ }^{2}$ Therefore, different approaches have been proposed to retain the dosage form in the stomach including bioadhesive system $^{3}$, swelling and expanding system $^{4}$, floating system ${ }^{5}$ and delayed gastric emptying devices. ${ }^{6}$ The principle of buoyant preparation offers a simple and practical approach to achieve increased gastric residence time for the dosage form and sustained drug release.

Salbutamol sulphate is a sympathomimetic amine which is used as a bronchodilator in the treatment of reversible bronchospasm. It is almost exclusively metabolized by conjugation to a 4'-Osulphate ester in the intestinal wall and liver. Salbutamol sulphate is freely soluble in water and has site-specific absorption in stomach and upper part of small intestine. ${ }^{7}$ The maximum plasma concentration 
occurs within $2.5 \mathrm{~h}$ and plasma half life ranges from 2.7-7.0 h. Urinary studies indicate elimination half life of approximately $4 \mathrm{~h}$. Salbutamol sulphate is given by mouth in a dose of 2 to $4 \mathrm{mg}$ three to four times a day. ${ }^{8}$ Salbutamol sulphate requires multiple daily drug dosage in order to maintain adequate plasma concentrations. Therefore, salbutamol sulphate has all the characteristics suitable for developing floating dosage form which would increase its oral bioavailability. In spite of having a lot of potential benefits floating drug delivery is associated with certain limitations. Drugs that irritate the gastric mucosa, those that have multiple absorption sites in the gastrointestinal tract, which undergo significant first pass metabolism and those that are not soluble and stable at gastric $\mathrm{pH}$ are not suitable candidates to be formulated as floating dosage forms. ${ }^{9}$

The aim of the present study was to formulate and characterize oral floating tablets of salbutamol sulphate using different polymers like carbopol, xantnan gum, HPMC-K4 MCR and HPMC- K100 MCR which acted as both buoyancy agents as well as a release-retarding polymer. Citric acid and sodium hydrogen carbonate were incorporated as gas generating agents. In order to develop the floating matrix tablet of salbutamol sulphate, it is necessary to optimize both the residence time of the system in the gastro intestinal tract and release rate of the drug from the dosage. The impact of polymer content and types upon release rate were investigated.

\section{MATERIALS AND METHODS}

Materials and reagents. Salbutamol sulphate was a gift sample from Amico Laboratories Ltd, Bangladesh. Carbopol, xantnan gum, HPMC-K4 MCR and HPMC- K100 MCR were obtained from ACI Ltd, Bangladesh. Sodium bicarbonate (Merck, Gernamny), citric acid (Loba, India), lactose and povidone K-30 were purchased from local market. The source of magnesium stearate and talc were Willfrid Smith Ltd, UK. Sodium hydroxide and potassium dihydrogen phosphate were procured from Merck, Germany. Distilled water was collected from the own research laboratory.

Table 1. Formulation of oral floating tablets of salbutamol sulphate based on different polymers.

\begin{tabular}{ccccccccccccc}
\hline $\begin{array}{c}\text { Formulation } \\
\text { Code }\end{array}$ & API & $\begin{array}{c}\text { Carbo- } \\
\text { pol }\end{array}$ & $\begin{array}{c}\text { Xanthan } \\
\text { gum }\end{array}$ & $\begin{array}{c}\text { HPMC- } \\
\text { K4 } \\
\text { MCR }\end{array}$ & $\begin{array}{c}\text { HPMC- } \\
\text { K100 } \\
\text { MCR }\end{array}$ & $\begin{array}{c}\text { Sodium } \\
\text { bicarbo- } \\
\text { nate }\end{array}$ & $\begin{array}{c}\text { Citric } \\
\text { acid }\end{array}$ & $\begin{array}{c}\text { Lac- } \\
\text { tose }\end{array}$ & $\begin{array}{c}\text { Povidone } \\
\text { K-30 }\end{array}$ & $\begin{array}{c}\text { Magnesium } \\
\text { Stearate }\end{array}$ & $\begin{array}{c}\text { Talc } \\
\text { Total } \\
\text { weight }\end{array}$ \\
\hline F-1 & 6 & 25 & - & - & - & 60 & 25 & 219 & 40 & 10 & 5 & 390 \\
F-2 & 6 & 45 & - & - & - & 60 & 25 & 199 & 40 & 10 & 5 & 390 \\
F-3 & 6 & - & 25 & - & - & 60 & 25 & 219 & 40 & 10 & 5 & 390 \\
F-4 & 6 & - & 45 & - & - & 60 & 25 & 199 & 40 & 10 & 5 & 390 \\
F-5 & 6 & - & 75 & - & - & 60 & 25 & 169 & 40 & 10 & 5 & 390 \\
F-6 & 6 & - & - & 25 & - & 60 & 25 & 219 & 40 & 10 & 5 & 390 \\
F-7 & 6 & - & - & 45 & - & 60 & 25 & 199 & 40 & 10 & 5 & 390 \\
F-8 & 6 & - & - & 75 & - & 60 & 25 & 169 & 40 & 10 & 5 & 390 \\
F-9 & 6 & - & - & - & 25 & 60 & 25 & 219 & 40 & 10 & 5 & 390 \\
F-10 & 6 & - & - & - & 45 & 60 & 25 & 199 & 40 & 10 & 5 & 390 \\
F-11 & 6 & - & - & - & 75 & 60 & 25 & 169 & 40 & 10 & 5 & 390 \\
F-12 & 6 & - & - & - & - & 60 & 25 & 244 & 40 & 10 & 5 & 390 \\
\hline
\end{tabular}

Weight of each ingredient was taken in mg.

Preparation of oral floating tablets of salbutamol sulphate. Salbutamol sulphate floating tablets were prepared by direct compression using different polymers like carbopol, xanthan gum, HPMC K4M and HPMC K100M as matrix former and sodium bicarbonate and citric acid as floating 
agents. Amount of various ingredients used in different formulations of floating tablets are presented in table 1 . Appropriate amounts of the mixture were accurately weighed with an electronic balance for the preparation of each tablet and finally the amounts were compressed using a Perkin-Elmer laboratory hydraulic press. Before compression, the surfaces of the die and punch were lubricated with magnesium stearate. All the preparations were stored in airtight containers at room temperature for further studies.

Physical tests. The compressed tablets were characterized by their physical properties. The average tablet weight was determined from 20 tablets. ${ }^{10} 20$ tablets of each of the formulations were measured diametrically. The values were displayed in millimeters (mm). Similarly, 20 tablets of each of the formulations were taken and thicknesses were measured in the same machine and the values were displayed in millimeters ( $\mathrm{mm}$ ). Hardness of the tablets was tested using a Monsanto tablet hardness tester. Friability of the tablets was determined in Roche friabilator. Tablet friability was calculated as the percentages of weight loss of 20 tablets after 100 rotations. ${ }^{10}$ The physical parameters for the compressed tablets were provided in table 2.

In vitro buoyancy study. According to the reliable reference of Rosa et al., (1994) ${ }^{11}$ the in vitro buoyancy was determined by floating lag time. The tablets were placed in a $100-\mathrm{mL}$ beaker containing $0.1 \mathrm{~N} \mathrm{HCl}$. The time required for the tablet to rise to the surface and float was determined as floating lag time shown in table 2.

Dissolution studies. Dissolution tests of salbutamol sulphate oral floating tablets were conducted according to the USP method (USP XXII) using apparatus 2. In all cases the conditions were maintained to be exactly the same, i.e. the rpm was maintained at 50 while the temperature maintained always at $37 \pm 0.5^{\circ} \mathrm{C}$ and phosphate buffer of pH 6.8 was used as dissolution media. The dissolution was carried out for 12 hrs. This was done to get a simulated picture of drug release in the in-vivo condition. The collected sample was first filtered, and then diluted before being assayed at $276 \mathrm{~nm}$ using UV spectrophotometer. The percentage of drug released was calculated and plotted against time.

\section{RESULTS AND DISCUSSION}

Physical parameters of oral floating tablets of salbutamol sulphate. The average weight of the tablets was found uniform and standardized at approximately $390 \mathrm{mg}$. The average diameter was found to be much consistent of $13.08 \mathrm{~mm}$ and the average thickness ranged from 2.09-2.19 $\mathrm{mm}$. On the contrary, the friability of the tablets of different formulations varied greatly ranging from 0.125$0.218 \%$. According to some authentic references the maximum friability range should be $0.5-1 \%{ }^{12}$ Since the friability values for none of the formulations exceeded $1 \%$, it does not pose any problem. Hardness of the tablets of the different formulations varied widely ranging from $5.60 \pm 0.025 \mathrm{~kg} / \mathrm{cm}^{2}$ being the lowest to $10.78 \pm 0.040 \mathrm{Kg} / \mathrm{cm}^{2}$ being the highest for $\mathrm{n}=20$. Since hardness greater than $5 \mathrm{~kg} / \mathrm{cm}^{2}$ is considered as acceptable, all the formulations are therefore thought to show the desired hardness. The tablets of F-11 had the greatest hardness (10.78 \pm $0.040 \mathrm{~kg} / \mathrm{cm}^{2}$ ).

Buoyancy and total floating test. From the results, it was observed that the buoyancy lag time and the total floating time was studied for all the formulations as shown in table 3. Results revealed that as the concentration of the ratio of polymer increases, the buoyancy lagging time decreases and constantly floated on dissolution medium. Floating lag times were found to be significantly controlled by sodium bicarbonate and citric acid content. It was reduced due to increase of amount of floating agent which caused rapid formation and entrapment of $\mathrm{CO}_{2}$ gas into the polymeric gel. The optimized formulation F-11 gives the best result in terms of the required lag time (1-2 minutes) and floating duration of $>12$ hrs.

Zero order model analysis. A drug is said to be released by zero order kinetics when the rate of release of drug is independent of the concentration of drug in the tablet. Percent release profile includes a 
plot of percent release of drug versus time. The dissolution data by zero order model revealed that maximum drug was released after 12 hours by the F1 (99.12\%), while F-11 released only (87.34\%) of drug at the same time and thus showing a more sustaining action than other formulations. Figure 1 shows the zero order release of salbutamol sulphate from all the formulations of the present study. At low concentration of polymer, the release of drug was generally seen more and at the high concentration of polymer, the release of drug was generally seen to decrease. This was applicable for all the polymers of the present study.

Table 2. Physical properties of oral floating tablets of salbutamol sulphate from formulation F-1 to F-12 (Number of sample = 20).

\begin{tabular}{cccccc}
\hline $\begin{array}{c}\text { Formulation } \\
\text { Code }\end{array}$ & $\begin{array}{c}\text { Weight variation } \\
(\mathrm{gm})\end{array}$ & $\begin{array}{c}\text { Diameter } \\
(\mathrm{mm})\end{array}$ & $\begin{array}{c}\text { Thickness } \\
(\mathrm{mm})\end{array}$ & $\begin{array}{c}\text { Friability } \\
(\%)\end{array}$ & $\begin{array}{c}\text { Hardness } \\
\left(\mathrm{kg} / \mathrm{cm}^{2}\right)\end{array}$ \\
\hline F1 & $386.0 \pm 0.3$ & $13.08 \pm 0.01$ & $2.09 \pm 0.08$ & 0.177 & $6.92 \pm 0.01$ \\
F2 & $390.0 \pm 0.5$ & $13.08 \pm 0.01$ & $2.11 \pm 0.07$ & 0.135 & $7.32 \pm 0.02$ \\
F3 & $386.0 \pm 0.3$ & $13.08 \pm 0.01$ & $2.09 \pm 0.09$ & 0.177 & $7.60 \pm 0.03$ \\
F4 & $391.0 \pm 0.5$ & $13.08 \pm 0.01$ & $2.11 \pm 0.07$ & 0.134 & $9.92 \pm 0.01$ \\
F5 & $379.0 \pm 0.4$ & $13.08 \pm 0.01$ & $2.12 \pm 0.06$ & 0.218 & $10.76 \pm 0.02$ \\
F6 & $378.0 \pm 0.8$ & $13.08 \pm 0.01$ & $2.09 \pm 0.10$ & 0.130 & $7.65 \pm 0.05$ \\
F7 & $390.0 \pm 0.4$ & $13.08 \pm 0.01$ & $2.12 \pm 0.20$ & 0.175 & $8.79 \pm 0.05$ \\
F8 & $391.0 \pm 0.9$ & $13.08 \pm 0.01$ & $2.13 \pm 0.21$ & 0.130 & $9.90 \pm 0.07$ \\
F9 & $386.0 \pm 0.3$ & $13.08 \pm 0.01$ & $2.15 \pm 0.22$ & 0.175 & $8.56 \pm 0.04$ \\
F10 & $379.0 \pm 0.4$ & $13.08 \pm 0.01$ & $2.16 \pm 0.31$ & 0.135 & $9.69 \pm 0.04$ \\
F11 & $390.0 \pm 0.5$ & $13.08 \pm 0.01$ & $2.19 \pm 0.32$ & 0.217 & $10.78 \pm 0.04$ \\
F12 & $390.0 \pm 0.5$ & $13.08 \pm 0.01$ & $2.09 \pm 0.08$ & 0.125 & $5.60 \pm 0.03$ \\
\hline
\end{tabular}

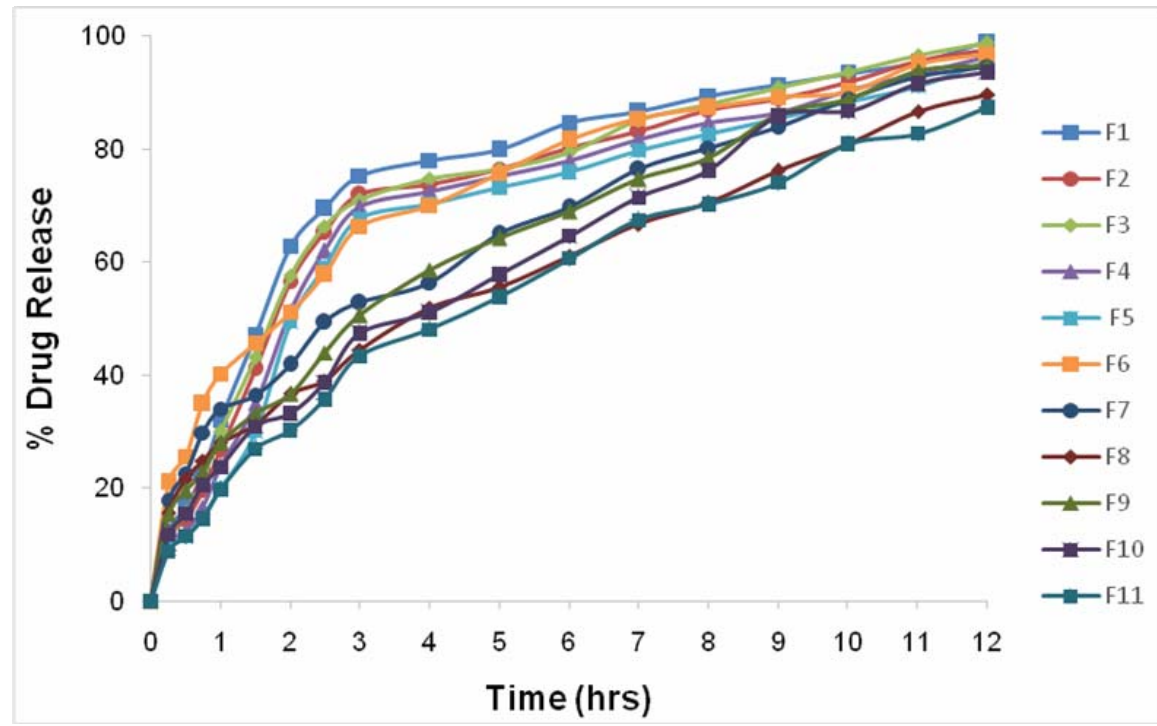

Figure 1. Zero order release profile of salbutamol sulphate for all the prepared formulations (F-1 to F-11).

Interpretation of effervescent salbutamol sulphate tablets. In F-12, polymer was absent while gas generating agents (sodium bicarbonate and citric acid) were present. The release profile showed
(Figure 2) that F-12 released $100 \%$ drug within 2 hours. So without polymer the formulated tablets showed normal effervescent tablets. 
Table 3. Floating behavior of oral floating tablets of salbutamol sulphate from formulation F-1 to F-12.

\begin{tabular}{ccc}
\hline Formulation code & Floating lag time (Minutes) & Duration of floating (Hours) \\
\hline F1 & $7-8$ & 6 \\
F2 & $5-6$ & 8 \\
F3 & $6-7$ & 7 \\
F4 & $4-5$ & 9 \\
F5 & $3-4$ & 10 \\
F6 & $4-5$ & 9 \\
F7 & $3-4$ & 10 \\
F8 & $2-3$ & 11 \\
F9 & $3-4$ & 10 \\
F10 & $2-3$ & 11 \\
F11 & $1-2$ & $>12$ \\
F12 & - & - \\
\hline
\end{tabular}

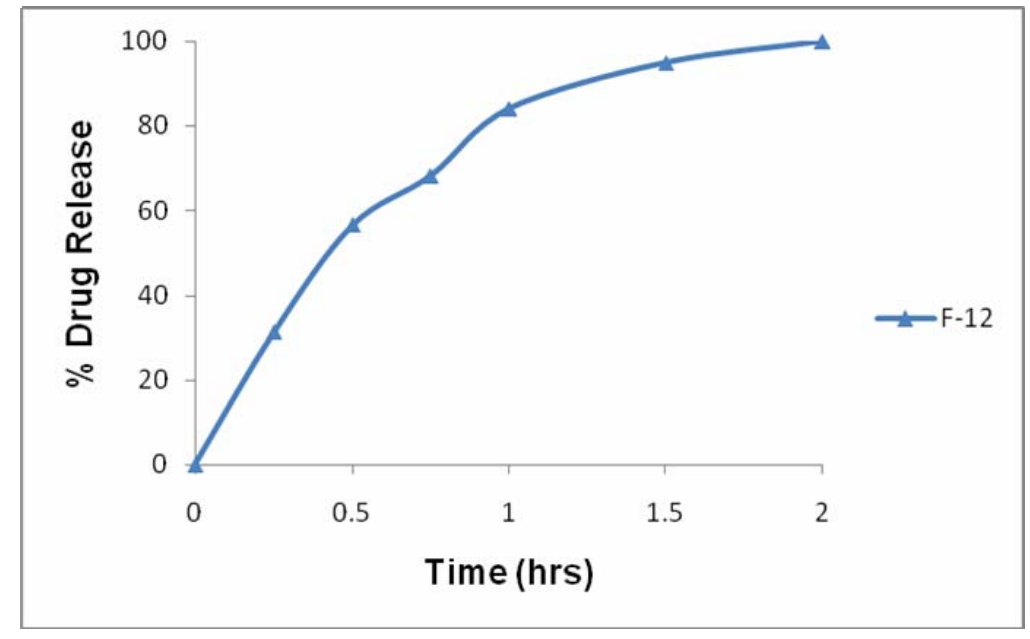

Figure 2. Release profile of effervescent salbutamol sulphate tablets of formulation (F-12).

Hence, we concluded that the effervescent tablets of salbutamol sulphate formulated by gas generating agents, sodium bicarbonate and citric acid without polymer could not control the drug release upto 12 hours. The incorporation of different ratios of different polymers shows well-controlled gastric floating tablets of salbutamol sulphate.

\section{CONCLUSION}

Floating drug delivery system has great promise to be a potential approach for gastric retention. Development of floating drug delivery system is beneficial for optimal therapy regarding efficacy, safety and patient compliance. F-11 exhibited higher retarding and better buoyancy properties more effectively than all other formulations. On the contrary, F-12 formulated by gas generating agents in which polymer was absent displayed the normal effervescent tablets of salbutamol sulphate. The result of this study revealed that same methodology can be used to formulate floating tablets for different drugs with optimum absorption to decrease dosage frequency.

\section{REFERENCES}

1. Hirtz, J. 1985. The GIT absorption of drugs in man: a review of current concepts and methods of investigation. Bri. J. Clin. Pharmacol. 19, 77-83. 
2. Singh, B.N. and Kim, K.H. 2000. Floating drug delivery systems: an approach to oral controlled drug delivery via gastric retention. J. Control. Rel. 63, 235-259.

3. Santus, G., Lazzarini, C., Bottoni, G., Sandefer, E.P., Page, R.C., Doll, W.J., Ryo, U.Y. and Digenis, G.A. 1997. An in vitro-in vivo investigation of oral bioadhesive controlled release furosemide formulations. Euro. J. Pharm. Biopharm. 44, 39-52.

4. Deshpande, A.A., Rhodes. C.T., Shah. N.H. and Malick, A.W. 1996. Controlled-release drug delivery systems for prolonged gastric residence: an overview. Drug. Dev. Indus. Pharm. 22, 531-539.

5. Menon, A., Ritschel, W.A. and Sakr, A. 1994. Development and evaluation of a monolithic floating dosage form for furosemide. J. Pharm. Sci. 83, 239-245.

6. Chawla, G., Gupta, P., Koradia, V. and Bansal, A.K. 2003. A means to address regional variability in intestinal drug absorption. Pharma. Tech. 27, 50-68.
7. Swarbrick, J. and Boylon, J.C. 2002. Encyclopedia of Pharmaceutical Technology. Marcel Dekker, New York. p. 896.

8. Lipworth, B.J., Clark, R.A., Dhillon, D.P., Charter, M.K., Palmer, J.B.D. and McDevitt D.G. 1989. Single dose and steady-state pharmacokinetics of $4 \mathrm{mg}$ and $8 \mathrm{mg}$ oral salbutamol controlled-release in patients with bronchial asthma. Euro. J. Clin. Pharmacol. 37, 49-52.

9. Lauritsen, K., Laursen, L.S. and Rask-Madsen, J. 1990. Clinical pharmacokinetics of drugs used in the treatment of gastrointestinal diseases. Clin. Pharmacokinet. 19, 94-125.

10. United State Pharmacopoeia. 2014. United States Pharmacopoeial Convention. Rockville, Maryland.

11. Rosa, M., Zia, H. and Rhodes, T. 1994. Design and testing in vitro of a bioadhesive and floating drug delivery system for oral application. Int. J. Pharm. 105, 65-70.

12. Ashnagar, A., Kouchak, M., Soltani, M. and Salimi, A. 2007. In vitro evaluation of some different brands of alprazolam tablets. J. Chem. 4, 563-573. 